\title{
STABILITY AND FREQUENCY CONTROL OF POWER GENERATING SYSTEMS BASED ON THE SLIDING MODE TECHNIQUE
}

\author{
التحكم فم تردد وإستقرار منظومات التوى الكهربية باستخدام نظرية الهيكل الهثنيره
}

\section{F. F. G. AREED}

Department of Electrical Engineering, Faculty of Engineering.

El-Mansoura University, El-Mansoura, EGYPT.

\author{
M. E. A. SACEM
}

$$
\begin{aligned}
& \text { منضص البحث: }
\end{aligned}
$$

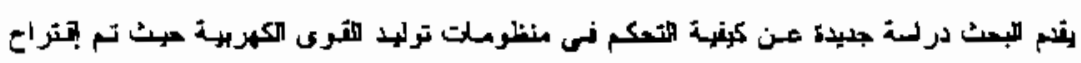

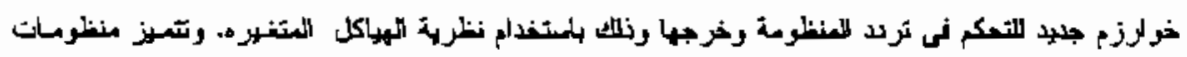

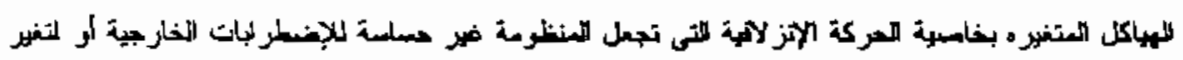

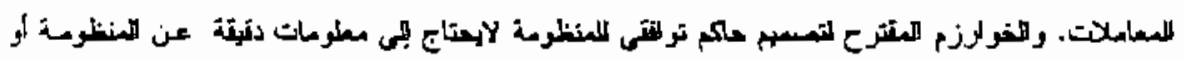

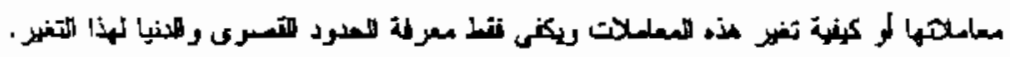

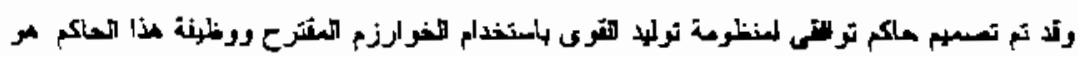

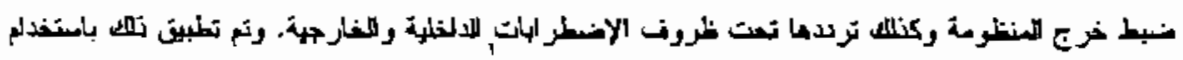

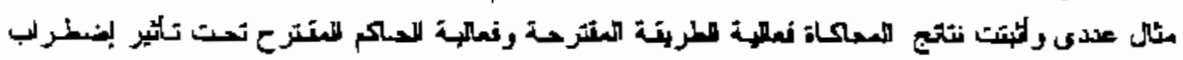

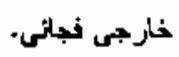

\section{ABSTRACT}

In the present paper, a new algorithm for solving the control problem in electrical power systems, is introduced. This new algorithm is based on the sliding mode property existing in variable structuro system (VSS). The resulting control law is discontinuous by its nature. However, it does not require accurate informations about the system parameters or its manner of variation. The only requirements are the maximum and minimum limits of variation for each paraneter.

An adapive controller is designed for an electrical power system, on the basis of that new algorithm. The main function of the controller is the frequency control of the electrical power system, meanwhile, it can be used for stability inprovement.

Theoretical and computational results, using that controller insure the frequency control property in the electrical power sysem model. The adaptive property verifies under rapid and wide range of parameters variation and also, under the effect of a unit step external disturbance. 


\section{INTRODUCTION}

Control of electrical power systems seems to be a complicated problem if we tried to solve it using clessical methods of control. This complication arises due to :

1. Lack of information about parameters variation.

2- Existence of external distubances.

Discontinuous control methods such as self-oscillatimg adaptive control $[2,9]$; high gain co-efficient control and those methods based on the theorems of liapounov and hyper-stability criterion, can not overcome the parameters variation in wide range as well as the effect of external disturbances.

Variable structure systems [1] are able to solve this problem This type of discontinuous control has an important property known as sliding mode [2]. Once in a control system a sliding mode is realized, the system becomes insensitive to parameters variation as well as, to extensal disturbances. For realizing sliding modes in control systems, a new general approach was doveloped [3]. This approach does not need any information about the parameters variation as well as, the level of external disturbances. Only, the upper and lower limits of these variations are to be known. On the basis of this approach, a new algorithm for adaptive control of electrical power systems, is developed.

The paper contains the development of a power system model. Then, the evaluation of VSS technique is presented.

\section{MATHEMATICAL MODEL}

Consider an intereonnected power system comprising $N$ subsystems The block diagram, representing the jith subsystem is shown in figure (1). Where reheat turbines are considered. The transfer functions of the rehest turbines are given by:

$$
G(s)=\frac{\Delta P_{d i}(s)}{\Delta X s i(s)}=\frac{1+s k_{r i} T_{r i}}{\left(1+s T_{n}\right)\left(1+s T_{u}\right)}, \quad i=12 \ldots \ldots \ldots . . . N
$$

If $\mathrm{K}_{\mathrm{i}_{i}}=1 ; G(s)$ reduces to $\frac{1}{1+8 \mathrm{~T}_{\mathrm{d}}}$. representing the transfer function of nonreheat turbines. The shown controller, in conventional case, has the transfer function $-k_{r_{i}}$. However, the case of VSS control the controller is modified as shown in figure (2).

Suppose that the dynamics of interconvected power system is described by the sate equation.

$$
\dot{x}=A(x, t) x+B(x, t) u+D(x, t) \cdot F(t) ; \quad x R^{n} ; U R^{*}, P^{\prime}
$$

where;

$A(x, t) \cdot(n x p)$ functional matrix of the state vector; 
$B(x, t)$ - (nxm) functional matrix of the controlling input; $D(x, t)$ - (nxl) functional matrix of extemal disturbance; $x$ - state vector; $u$ - controlling input; $F$ - external disturbance. Matrix $A(x, t)$ is in the form:

$$
A(x, t)=\left[\begin{array}{llll}
A_{11} & A_{21} & A_{1 i} & A_{1 N} \\
A_{21} & A_{22} & & \\
& & & \\
A_{i 1} & & A_{i i} & \\
A_{N 1} & A & A_{N i} & A_{N M}
\end{array}\right]
$$

matrix $B(\dot{x}, t)$ has the form;

$B(x, t)=\left[B_{1}\right.$

$\mathrm{B}_{2}$ $\mathbf{B}_{\mathbf{i}}$ $\left.\mathrm{B}_{\mathrm{N}}\right]^{\mathrm{T}}$

and matrix $D(x, t)$ is given by
$D(x, t)=\left[D_{1}\right.$
$\mathrm{D}_{2}$
$\mathrm{D}_{\mathrm{i}}$ $\left.D_{\mathrm{H}}\right]^{\mathrm{T}}$.

Considering the i th subsystem

$$
\begin{aligned}
& A_{i j}=\left[\begin{array}{llllll}
0 & 0 & 0 & 0 & 0 & 0 \\
0 & 0 & 0 & 0 & 0 & 0 \\
0 & 0 & 0 & 2 \pi \mathbf{T} . \mathbf{T}_{\mathrm{ij}} & 0 & 0 \\
0 & 0 & 0 & 0 & 0 & 0 \\
& & & & & \\
0 & 0 & 0 & 0 & 0 & 0 \\
0 & 0 & 0 & 0 & 0 & 0 \\
0 & 0 & 0 & 0 & 0 & 0
\end{array}\right] ; \mathrm{i}=1,2, \ldots, \mathrm{N} ; \\
& \mathbf{B}_{\mathrm{i}}=\left[\begin{array}{llllll}
0 & \frac{1}{\mathrm{~T}_{\mathrm{Bi}}} & 0 & 0 & 0 & 0
\end{array}\right]^{\mathrm{T}} \quad ; \mathrm{i}=1,2, \ldots, \mathrm{N} ; \\
& \mathrm{D}_{\mathrm{i}}=\left[\begin{array}{llllll}
0 & 0 & 0 & \frac{-K_{p 1}}{T_{p 1}} & 0 & 0
\end{array}\right]^{\top} \quad ; \mathrm{i}=1,2, \ldots, \mathrm{N}
\end{aligned}
$$


And

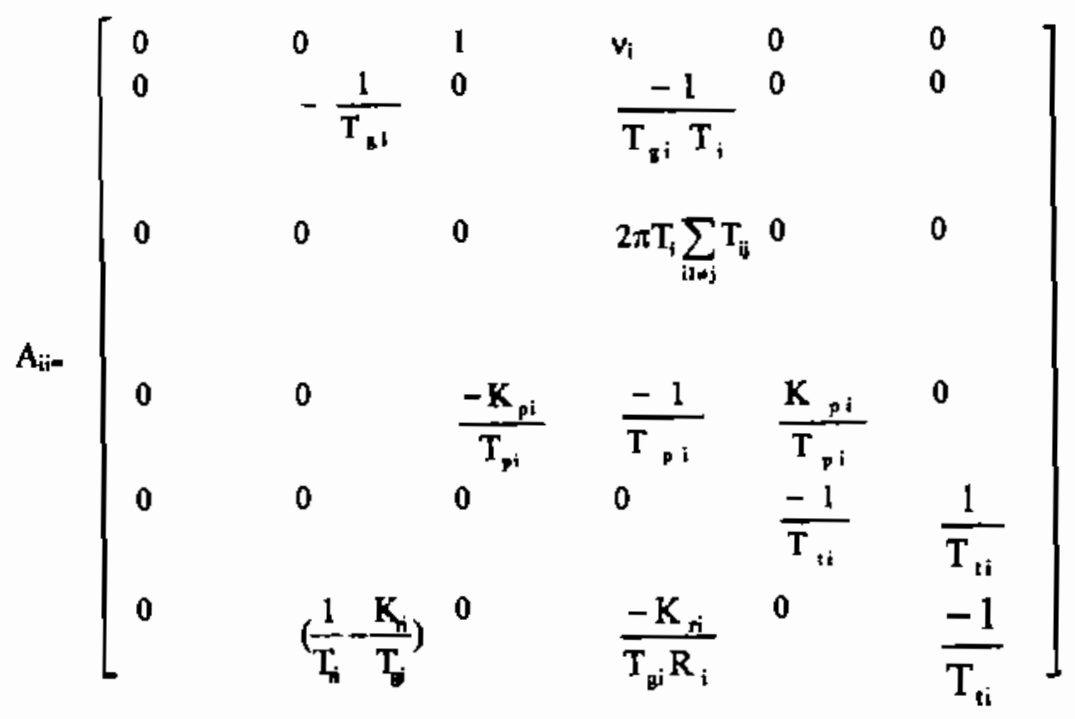

where :

$\mathbf{k}_{\mathrm{i}}$ : = reheat co-efficient;

$T_{6 i}:=$ nurbine time constant;

$T_{n}: \approx$ relseat time constant;

$T_{p}:$ = governor time constant; $v_{i}:=$ frequency bias setting;

$T_{\mathbf{p}}:=$ power system time constant;

$K_{\text {oi }}:=$ power system gain;

$T_{\mathrm{ij}}$ : a synchronizing co-efficient between subsystems i \& j;

$\mathrm{R}_{\mathrm{i}}$ : = speed regulation due to governor action;

\section{STATEMENT OF THE PROBLEM}

It is required to design a controller, which generates an acruating sigmal to control the frequency deviation $\Delta f_{i}$, as well ss the tie - line power change $\Delta P_{\text {tid }}$ resulting from sudden changes in the load $\Delta P_{d i}$.

The following set of minimum requiremats are stated [4] by the North Americas Power Systom Interconnection Committee ;

i) The static frequency error following a step load change max be zero;

i) The transient frequency swings should not exceed $\pm 0.02 \mathrm{~Hz}$ under normal conditions

ii) The static change in tie-lime flow following a step change in each muxt be zero,

iv) The individual generators within each area should divide their loads for optimum economy. 


\section{A NEW ALGORIHM FOR REALIZING A SLIDING MODE IN POWER SYSTEMS} follows :

The vectorial control problem could be divided into m-scalar problems as

From the state equation (2) we can write :

$$
\begin{aligned}
x=A(x, t) \cdot x(t) & +b^{1}(x, t) u_{1}+b^{2}(x, t) u_{2}+\ldots \ldots . .+ \\
& +b^{m}(x, t) u_{m}+D(x, t) \cdot F(t) \ldots \ldots \ldots \ldots
\end{aligned}
$$

where :

$b^{\prime}(x, t) ; b^{2}(x, t) \ldots . . ; b^{m}(x, t)$ are the colurms of matrix $b(x, t)$. byperplanes

Heace, a set of sliding modes could be organized simultaneously on the mwhere :

$$
\sigma_{1}, \sigma_{2}, \ldots \ldots \ldots \ldots, \sigma_{m}
$$

$$
\begin{aligned}
& \sigma_{1}=C^{1 T} \times ; C^{1}-(n) \text { vector column } ; x \in R^{n} \\
& \sigma_{2}=C^{2 T} x^{1} ; C^{2}-(n-1) \text { vector columo } ; x^{1} \in R^{n-1} \\
& \sigma_{m}=C^{m T} x^{m-1} ; C^{m}-(n-m+1) \text { vector column } ; x^{m-1} \in R^{n-m+1}
\end{aligned}
$$

The elements of vector columns $\mathrm{C}^{1}, \mathrm{C}^{2}, \ldots . . \mathrm{C}^{*}$ could be determined using the standard coefficient method [5]. The necessary and sufficient condition for realizing a sliding mode on the plane $\sigma_{1}$ is $\sigma_{1} \cdot \dot{\sigma}_{1}<0$ [2]. To achieve this condition we sharl require that the following conditions must be realized :

$C^{\prime T} \quad b^{1}(x, t) \neq 0$.

$C^{\prime T} \quad b^{\prime}(x, t) . \phi_{1}\left(\sigma_{1}\right)<0$ when $\sigma_{1}>0$

$C^{1 T} \quad b^{1}(x, t) . \phi_{1}\left(\sigma_{1}\right)<0$ when $\sigma_{1}>0$

$\left|C^{i T} \quad b^{1}(x, t) . \quad \phi_{1}\left(\sigma_{1}\right)\right|<\mid C^{\top T} \quad A(x, t) \cdot x(t)+C^{\top T} \quad h^{2}(x, t) u_{2}+\ldots$ $+C^{l T} b^{m}(x, t) u+C^{l T} D(x, t) \cdot F(t) \mid$

Condition (4a) could be realized if the following conditions were satisfied :

i) The element $C_{\text {nant }}$ in the vector row $C^{1 T}$ has a nouzero value, i.e. if $\mathrm{C}^{\mathrm{TT}}$ had the form:

$\mathrm{C}^{\mathrm{IT}}=\left(\mathrm{C}_{1}, \mathrm{C}_{2}, \ldots . ., \mathrm{C}_{r-\mathrm{m}+1}, 0,0, \ldots, 0\right)$ 
ii) The vector columb bas the form:

$b^{\prime}(x, t)=\left[\begin{array}{llllll}0 & 0 & \ldots . . . & b_{m} & b_{m-1} & b_{1}\end{array}\right]^{\top}$

Conditions (4b), (4c), and (4d) could be realized, if the function $\phi_{1}\left(\sigma_{1}\right)$ was chosen as a nonlinear multi-valued function having the following properties :

a- muti-valued and limited;

$b$ - closed at $\sigma_{1}=0$ as a set and limited;

c- semi-contiruous at $\sigma_{1}=0$;

d- values of $\sigma_{1}, \sigma_{2}, \ldots \ldots, \sigma_{m}$ in the neibourhood of $\phi\left(\sigma_{0}, t\right) \in \phi\left(\sigma_{0}\right)$.

The above mentioned multi-valued function is shown in figure (3). After satisfying conditiona (4a), (4b), (4c) and (4d) we get;

$$
\begin{aligned}
\sigma_{1}= & C^{i T} x \ldots \\
\dot{\sigma}_{1}= & C^{1 T} \dot{x} \\
= & C^{l T}\left[A(x, t), x(t)+b^{1}(x, t) \phi_{1}\left(\sigma_{1}\right) .+b^{2}(x, t) u_{2}+\right. \\
& \left.\quad+b^{3}(x, t) u_{3}+\ldots \ldots+b^{m}(x, t) u_{w}+D(x, t) \cdot P(t)\right]
\end{aligned}
$$

From (6a) and (6b) we have ;

$$
\begin{aligned}
\sigma_{1} \cdot \dot{\sigma}_{1} & =\sigma_{1} \cdot C^{\mathrm{lt}} b^{1}(x, 1) \phi_{1}\left(\sigma_{1}\right)+\left(\sigma_{1}\right) \cdot C^{\mathrm{lt}}[A(x, t) \cdot x(t)+ \\
& \left.+b^{2}(x, 1) u_{2}+\ldots \ldots+b^{\alpha t}(x, t) \cdot F(t)\right] . .
\end{aligned}
$$

From (7) it is easy to show that the inequality $\sigma_{1} . \sigma_{1}<0$ will be akways satisfied ; ie. there will be a permanent sliding motinn on the hyperplane $\sigma_{1}$.

Existenee of a sliding mode on the plane $\sigma_{1}$ means that the motion of system (3) can be described by the following equations :

$$
\begin{aligned}
& x=A(x, t) \cdot x(t)+b^{2}(x, t) \cdot u_{2} .+\ldots \ldots .+b^{m}(x, t) \cdot u_{m} \\
& +D(x, t) \cdot F(t)+b^{1}(x, t) \cdot \zeta_{1} \ldots \ldots . \\
& C^{I T} x(t)=0
\end{aligned}
$$

where :

$\zeta_{1}=$ a single valued (scalar) function or the first component of the nonlinear predetermined vector function - (additional controlling input ) and is given by :

$$
\begin{array}{r}
\zeta_{1}=\left[C^{\prime T} b^{\prime}(x, t)\right]^{-1} \cdot\left\{-C^{1 T}\left[A(x, t), x(t)+b^{2}(x, t) d u_{2}+. .\right.\right. \\
\left.\left.+b^{*}(x, t)-u+D(x, t) \cdot F(t)\right]\right\}
\end{array}
$$


Similarly, it is possible to establish another sliding modes on the hypetplanes $\sigma_{2}, \ldots \ldots . \sigma_{\mathrm{m}}$ using tho same technique. The multi-valued function could be generated using a multiplier as shown in figure (4).

A flow-chart for a computer program to carry-out the suggested algorithm is shown in figure (5).

In the flow chart, the following symbols are used

i) $A_{0}$ and $B_{0}$ are the steady stato matrices for the controlled system

ii) $w_{0}:=a$ scalar which determines the response speed of the controlled system at steady-state [6].

ii)NT : = number of computation points ;

NK1: = number of points from starting till applying the change external disturbance NK: = number of points from starting till applying the adaptive control vector ;

NST: = addirional variable cyclo .

iv) $r_{i}=x_{i}-x_{x_{i}}-$ error between the state vectors of the system under consideration and its steady-srate values.

\section{EXAMPLE}

Consider an interconnected power system consising of two subsysterns (identical sceam plants). The case of nonrebeat turbimes will be considered.

For comparison purposes, The same values of the systen parameters contained in [7] are used ;

$$
\begin{array}{lll}
P_{1}=0.425 \text { p.u. } M W, & T=0.39, & K_{p}=120 \mathrm{~Hz} / \text { p.u. } M W, \\
R=2.4 \mathrm{~Hz} / \text { p.u. } \mathrm{MW}, & T_{g}=0.85, & T_{t}=20 \mathrm{Sec} ., \\
T=10 \mathrm{Sec}, & K_{4}=1.0, & 2 \pi T_{12}=0.545 \text { p.u. }
\end{array}
$$

The system matrices are given by ;

$$
\begin{aligned}
& A_{11}=A_{22}=\left[\begin{array}{lllll}
0 & 0 & 1 & 0.425 & 0 \\
0 & -12.5 & 0 & -5.206 & 0 \\
0 & 0 & 0 & 0.545 & 0 \\
0 & 0 & -6 & -0.500 & 0 \\
0 & 3.33 & 0 & 0 & -3.33
\end{array}\right] \quad A_{12}=A_{21}=\left[\begin{array}{lllll}
0 & 0 & 0 & 0 & 0 \\
0 & 0 & 0 & 0 & 0 \\
0 & 0 & 0 & -0.545 & 0 \\
0 & 0 & 0 & 0 & 0 \\
0 & 0 & 0 & 0 & 0
\end{array}\right] \\
& B_{1}=B_{2}=\left[\begin{array}{llllll}
0 & 12.5 & 0 & 0 & 0 & 0
\end{array}\right]^{\mathrm{T}} \\
& D_{1}=D_{2}=\left[\begin{array}{llllll}
0 & 0 & 0 & 0 & 0 & 1
\end{array}\right]^{\mathrm{T}}
\end{aligned}
$$

Consider two diferent control schemes, where no physical constraints are imposed on the system variablcs.

i) For conventional control, the control laws are assumed to be [7];

$$
u_{i}=-0.7 x_{i 1}, \quad i=1,2
$$


i) For VSS control, using the new algorithm we obtain; The switching hyperplenes are given by ;

$$
\begin{aligned}
& \sigma_{i}=C_{i}^{T} \cdot x_{i}, i=1,2, \text { where; } \\
& C_{i}=\left[\begin{array}{llll}
0.082-33.2 & 0 & 6.02 & 33.3
\end{array}\right]
\end{aligned}
$$

Figure (6) shows the simulation results of $\Delta F_{l}, \Delta P_{g i}, \Delta P_{i=}, \Delta F_{2}, \Delta P_{B^{2}}$ when subsystem $\underline{l}$ is sabjected to a step load change of 0.01 p.u. Resulis using comventionat control are also included for comparison purpose.

\section{CONCLUSION}

Controller for an electrical power system is suggested, using the main property of VSS-(sliding modes). This controller insures the adaptive control of the system and its invariance to the external disturbance. Design of this controller does not need information ahout either the system parameter or exterual disturbance variation. It is required onty to know their upper and lower limits of variation.

\section{REFERENCES}

1. UTKIN, V.I., “ Varisble Structure Systems with Sliding Modes “, IEEE TAC, Vol. AC-22, No. 2, 1977, pp. 212-222.

2. KAUTSKY, J, NICHOLS, N. K \& DOOREN, P. VAN 'Robust Poie Assignment in Linear State Feed-back" International Journa' of Control, 41, 1985, pp. 1129 1155.

3. YOUNG, KKD., "Design of Variable Structure Model Following Control Systems", IEEE TAC, Vol. 23, No. 6, 1978, pp. 1079-1085.

4. FOSHA, C.E. \& ELGERD, O.1., "The Megawatt-Frequency Control Problem; A New Approach Via Optimal Control Theory", IEEE Trans, 1970, PAS 89, pp. 363577.

5. AMIN, M H. \& HASSAN, M. M. " A Decentralized Compensator for Load Frequency Conirol", Journal A, Vol 28, No. 1, 1987.

6. WATH-CHUN CHAN \& YUAN-YIH HSU, "ConLrol of Power Systein Using the Concept of Variable Structure, Proceding of The First Symposiumon Electric Power", Taiwen, 1980, pp. 19-37.

7. NANDA, J. \& KAUL, B.L., 'Automatic Generation Control of An Interconnected Power System", IEE, 1978, Vol 125, No. 5, pp.385-390.

8. GUTMAN, S., 'Uncertain Dynamical System - A Liapunov Min - Max Approach, IEEE TAC, Vol AC-24, No. 3, 1979, 437-443.

9. WANG, Y., ZHOU, r., \& WEN, C., “ New Robust Adaptive Load Frequency Control with System Parametric Uncertainities", IEE PROC. 141, pt. D., 1994, 3, pp.184-190. 
Mansoura Englneering Journal, (MEJ), Vol. 22, No. 4. December 1997. E. 32
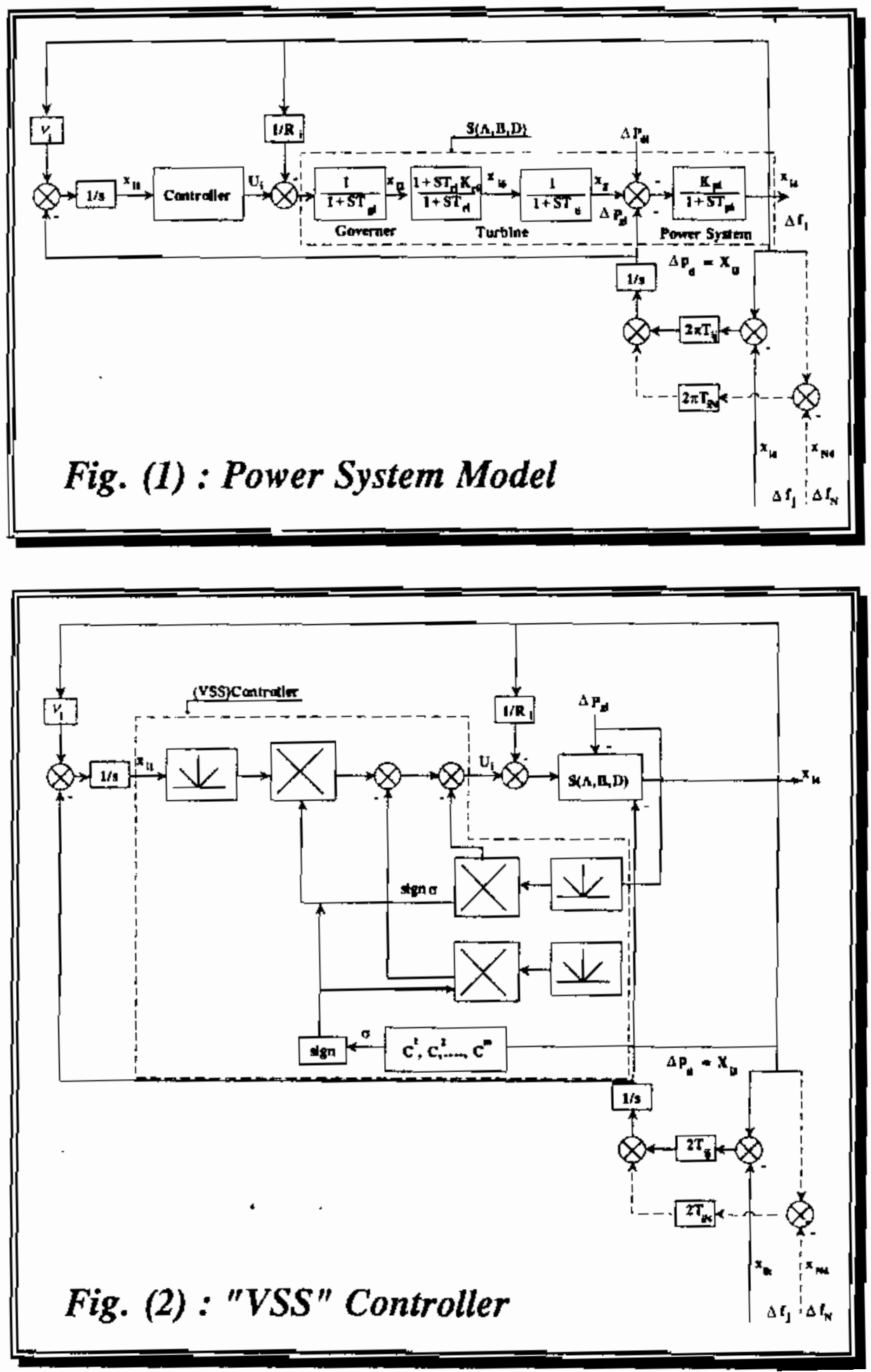


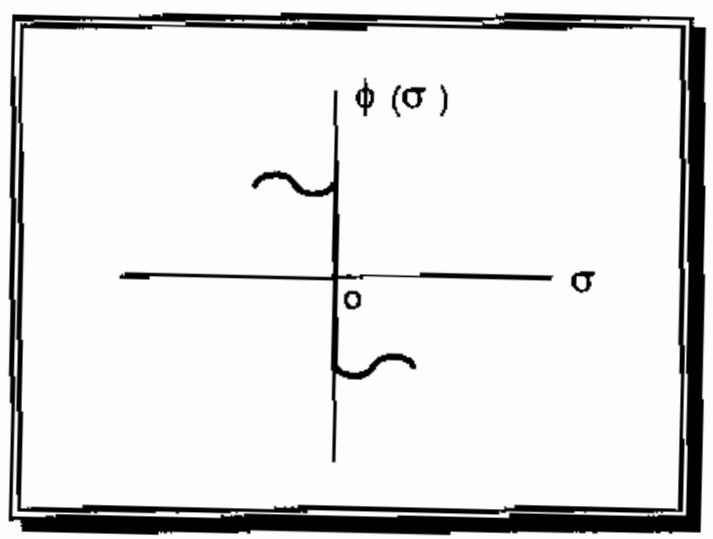

Fig. (3) : Multivalued Function.

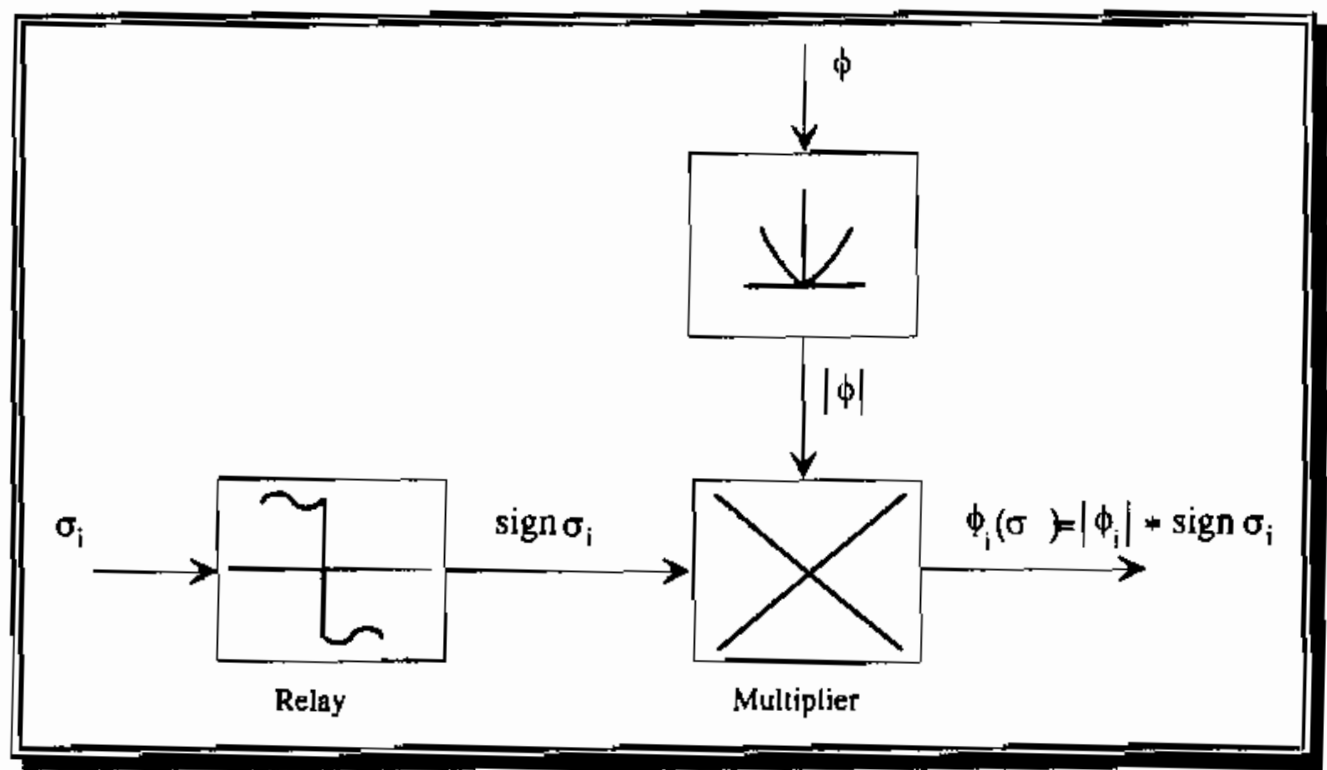

Fig. (4) : Generation Of Multivalued Function. 


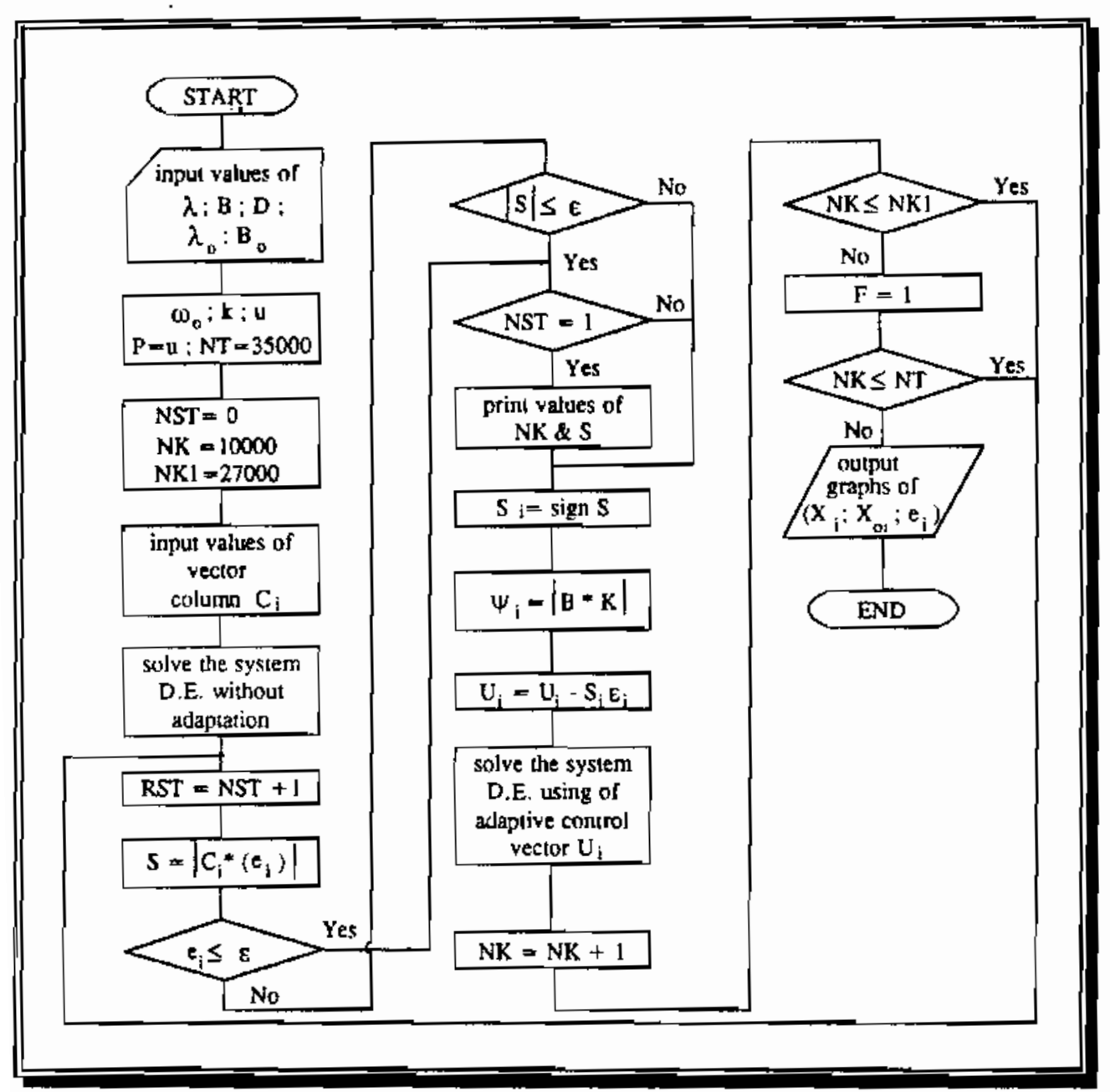

Fig. (5) : Flow Chart 

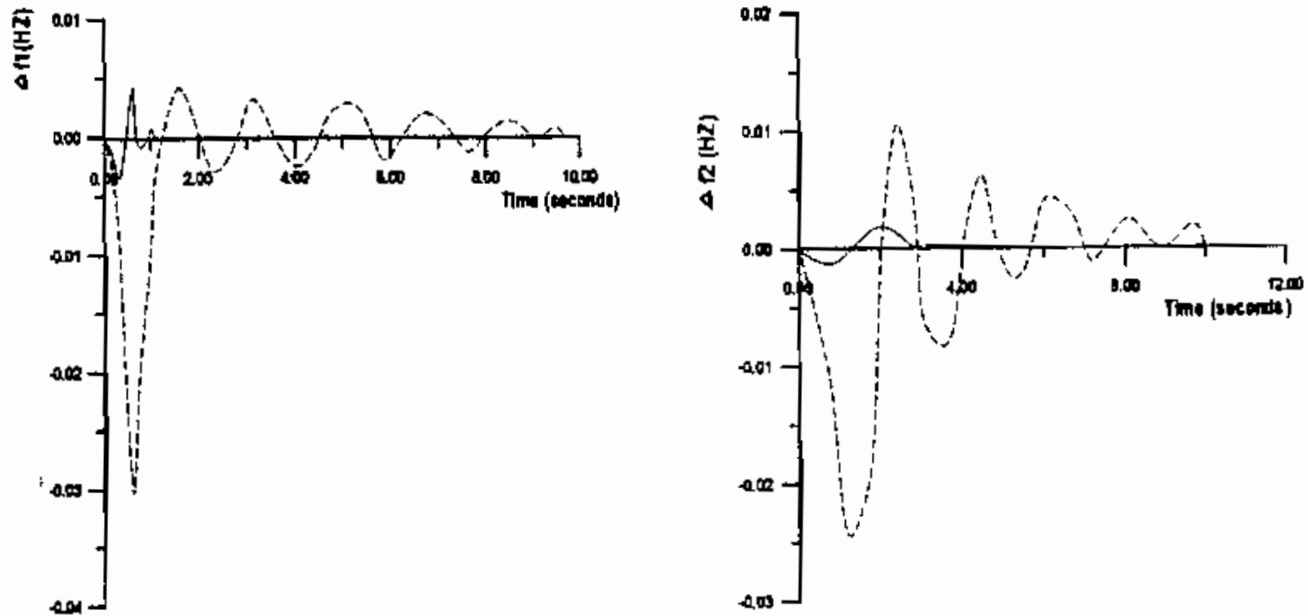

(a)

(d)
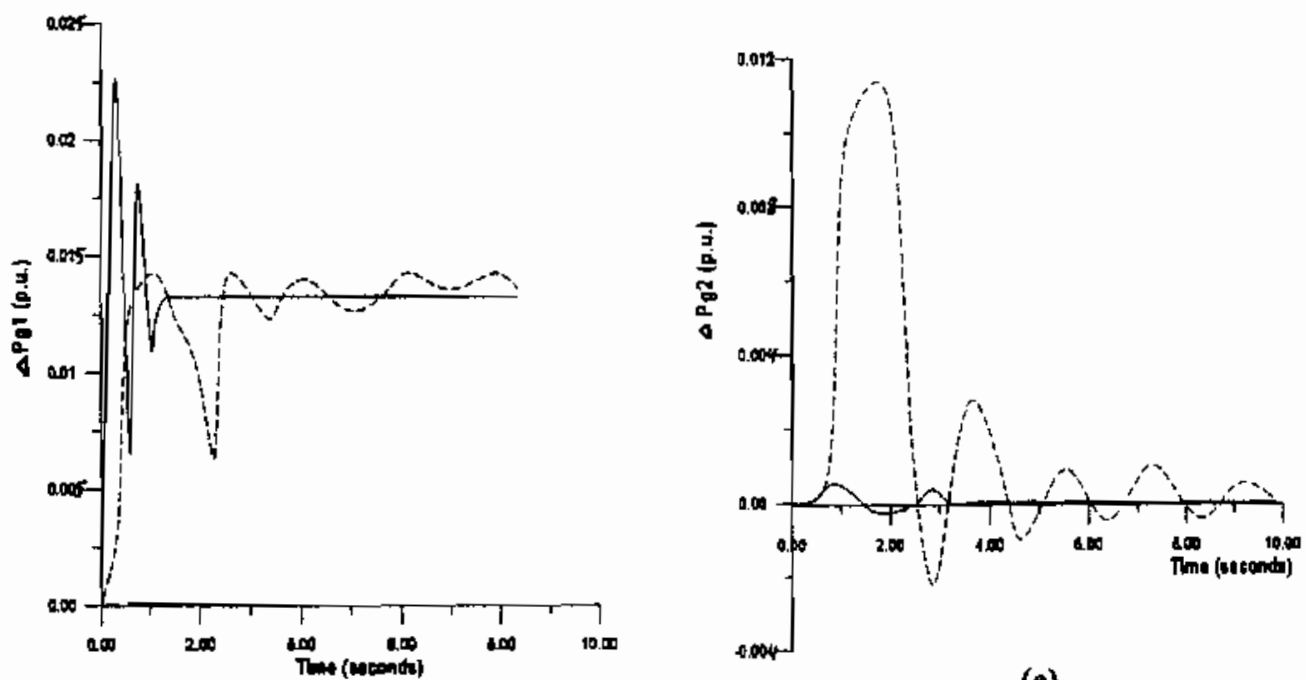

(b)

(e)

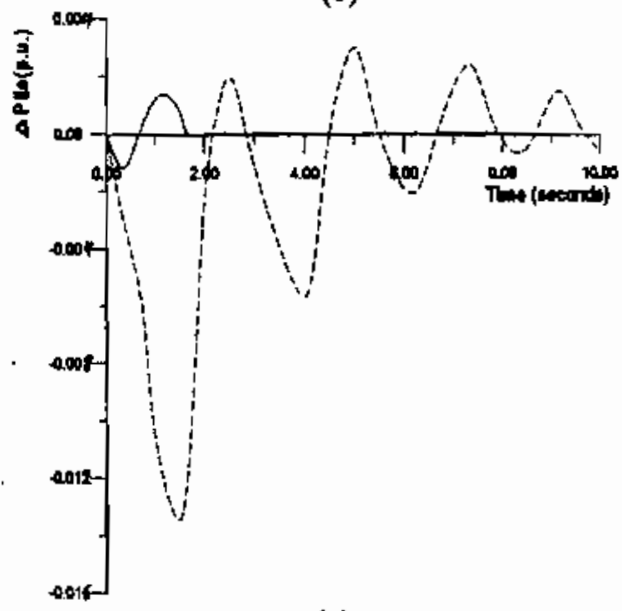

__ (VSS) Controller

\section{..... Conventional Contoller}

(c)

Fig. 6 Simulation Result 